\title{
Heterogeneous reactions of suspended parathion, malathion, and fenthion particles with $\mathrm{NO}_{3}$ radicals
}

\author{
Changgeng Liu, Bo Yang, Jie Gan, Yang Zhang, Miao Liang, Xi Shu, Jinian Shu* \\ Research Center for Eco-Environmental Sciences, Chinese Academy of Sciences, Beijing 100085, China
}

\section{A R T I C L E I N F O}

\section{Article history:}

Received 19 September 2011

Received in revised form 12 December 2011

Accepted 13 December 2011

Available online 5 January 2012

\section{Keywords:}

Organophosphorus pesticides

Heterogeneous reaction

$\mathrm{NO}_{3}$ radicals

GC/MS

Aerosol mass spectrometry

\begin{abstract}
A B S T R A C T
Organophosphorus pesticides (OPPs) emit into the atmosphere in both gas and particulate phases via spray drift from treatments and post-application emission, but most of their degradations in the atmosphere are not well known. In this study, the heterogeneous reactions of nitrate $\left(\mathrm{NO}_{3}\right)$ radicals with three typical OPPs (parathion, malathion, and fenthion) absorbed on azelaic acid particles are investigated using an online vacuum ultraviolet photoionization aerosol time-of-flight mass spectrometer (VUV-ATOFMS). The reaction products observed with the VUV-ATOFMS are identified on the basis of GC/MS analysis of the products in the reaction between $\mathrm{NO}_{3}$ radicals and the coating of the pesticide. Paraoxon is identified as the only product of parathion; malaoxon and bis(1,2-bis-ethoxycarbonylethyl)disulfide as the products of malathion; fenoxon, fenoxon sulfoxide, fenthion sulfoxide, fenoxon sulfone, and fenthion sulfone as the products of fenthion. The degradation rates of parathion, malathion, and fenthion under the experimental conditions are $5.5 \times 10^{-3}, 5.6 \times 10^{-2}$, and $3.3 \times 10^{-2} \mathrm{~s}^{-1}$, respectively. The pathways of the heterogeneous reactions between the three OPPs and $\mathrm{NO}_{3}$ radicals are proposed. The experimental results reveal the possible transformations of these OPPs through the oxidation of $\mathrm{NO}_{3}$ radicals in the atmosphere.
\end{abstract}

(c) 2011 Elsevier Ltd. All rights reserved.

\section{Introduction}

Organophosphorus pesticides (OPPs) are a group of very effective compounds widely used in agriculture and residence as insecticides and herbicides (Jauregui et al., 2003). OPPs are regarded as less persistent in the environment than organochlorine pesticides (OCPs) (Ferrando et al., 1992), and this family of chemicals is one of the substitutes for OCPs, which was banned for use in the 1970s (Vonderheide et al., 2003). It is well known that OPPs have genotoxicity (Cakir and Sarikaya, 2005), cytotoxicity (Giordano et al., 2007), reproductive toxicity (Pina-Guzman et al., 2005), and irreversible inhibitory activity to acetylcholinesterase (Jauregui et al., 2003). In addition, not only OPPs themselves but also their degradation products put humans at risk, because their degradation products in the environment may be more toxic than their parent chemicals (van den Berg et al., 1999). As a result of wide application, not only waters and soils but also the air is contaminated with OPPs (Kosikowska and Biziuk, 2010). This is due to spray drift from the application (van den Berg et al., 1999) and the post-application emission including volatilization (van den Berg et al., 1999) and wind erosion (Kosikowska and Biziuk, 2010). Besides their wet and dry deposition, OPPs in the atmosphere

\footnotetext{
* Corresponding author. Tel.: +86 10 62849508; fax: +86 1062923563

E-mail address: jshu@rcees.ac.cn (J. Shu).
}

can be removed by the photolysis and the reactions with atmospheric oxidants, such as hydroxyl $(\mathrm{OH})$ radicals, ozone $\left(\mathrm{O}_{3}\right)$, and nitrate $\left(\mathrm{NO}_{3}\right)$ radicals (Atkinson, 1995).

The $\mathrm{NO}_{3}$ radical plays an important role in the nighttime atmosphere, its reactivity is comparable to that of $\mathrm{OH}$ radicals in the daytime atmosphere (Karagulian and Rossi, 2005). The concentration of $\mathrm{NO}_{3}$ radicals is reported to reach values of up to $4.0 \times$ $10^{7}$ molecules $\mathrm{cm}^{-3}$ in the stratosphere (Naudet et al., 1989) and $2.0 \times 10^{9}$ molecules $\mathrm{cm}^{-3}$ in the troposphere at nighttime (Platt et al., 1980). Despite these significant concentrations, few studies on the heterogeneous reactions of airborne OPPs with $\mathrm{NO}_{3}$ radicals have hitherto been performed (Liu et al., 2011).

Parathion (0,O-diethyl $O$-(4-nitrophenyl) phosphorothioate), malathion (S-[1,2-bis(carbethoxy)ethyl]-O,O-dimethyl dithiophosphate), and fenthion (O,O-dimethyl $O$-[3-methyl-4-(methylthio)phenyl] phosphorothioate) selected as the samples in this study are three representative kinds of OPPs, widely used in agrochemical applications. These OPPs are expected to exist in both gas and particle phases in the atmosphere on the basis of their vapor pressures ranging from $10^{-3}$ to $10^{-4} \mathrm{~Pa}$ at room temperature. Great efforts have been made into the studies on the three OPPs, but most of which focused on the treatment technologies, toxic effects, and the metabolites in plants, waters and soils (Cabras et al., 1993; Minelli et al., 1996; Kaur et al., 1997; Bavcon et al., 2003; Pico et al., 2007; Wu and Linden, 2008; Slotkin et al., 2009; Fan et al., 
2011). The aim of this study is to identify the products of suspended parathion, malathion, and fenthion particles in the reactions with $\mathrm{NO}_{3}$ radicals, and explore their reaction pathways. The results may help reveal the transformation processes of these OPPs in the atmosphere through oxidation by $\mathrm{NO}_{3}$ radicals, and provide fundamental information for evaluating the harmful effects of the three OPPs and their products in the atmosphere.

\section{Experimental section}

\subsection{Chemicals}

Parathion (98.3\%, Dikma), malathion (98.4\%, Dikma), fenthion (98.9\%, Dikma), azelaic acid (99\%, NRSCRD, China), fuming nitric acid (95\%, Beijing Lisui Chemical Factory), $\mathrm{P}_{2} \mathrm{O}_{5}$ (98\%, Sinopharm Chemical Reagent Co., Ltd.), and absolute ethyl alcohol (99.7\%, Sinopharm Chemical Reagent Co., Ltd.) are used in the experiment. Nitrogen (99.99\%) is purchased from Beijing Huayuan Gas Chemical Industry Co. Ltd. and dichloromethane (chromatographic grade) from J. T. Baker Co.

\subsection{Experimental setup}

The experimental setup has been described in detail elsewhere (Zhang et al., 2010a). Briefly, it consists of an aerosol generator, a reaction chamber, and analytic instruments.

The suspended pesticide particles are generated through the homogeneous nucleation. The aerosol generator is an electric tube furnace equipped with two tandem quartz tubes $(50 \mathrm{~cm}$ (length) $\times$ $3 \mathrm{~cm}$ (inner diameter)), each with an independent temperature controller (from the room temperature up to $523 \mathrm{~K}$ ). Azelaic acid is employed to produce nuclei due to its little reactivity with $\mathrm{NO}_{3}$ radicals in the previous studies (Yang et al., 2011). Azelaic acid is placed in the first tube ( $418 \pm 1 \mathrm{~K}$ for fenthion, $428 \pm 1 \mathrm{~K}$ for malathion and parathion), while the pesticide sample in the second tube ( $403 \pm 1 \mathrm{~K}$ for fenthion, $413 \pm 1 \mathrm{~K}$ for malathion and parathion). A $\mathrm{N}_{2}$ stream with a volumetric flow rate of $0.6 \mathrm{~L} \mathrm{~min}^{-1}$ flows through the first tube bringing the nuclei into the second tube. In the second tube, the azelaic acid nuclei are coated by the pesticide. The thickness of the coating is controlled by adjusting the temperature of the quartz tube and the flow rate of $\mathrm{N}_{2}$. The size and concentration of particles are monitored with a scanning mobility particle sizer (SMPS), which is composed of a differential mobility analyzer (DMA, TSI 3081) and a condensation particle counter (CPC, TSI 3010). The geometric mean diameters of parathion, malathion, and fenthion particles are 390, 395, and $373 \mathrm{~nm}$, respectively. The initial mass concentrations of parathion, malathion, and fenthion in the chamber are 572,654 , and $407 \mu \mathrm{g} \mathrm{m}^{-3}$, respectively, which are calculated on the basis of the mass concentrations and size distributions of particles before and after coated by the pesticide.

The reaction chamber consists of a thin-walled open head stainless steel drum $(50 \mathrm{~cm}$ (outer diameter) $\times 60 \mathrm{~cm}$ (height)) and a thin Tedlar polyvinyl fluoride (PVF) film bag $(50 \mathrm{~cm}$ (diameter) $\times 50 \mathrm{~cm}$ (length)). The PVF bag is used to keep one atmospheric pressure in the aerosol reaction chamber. The volume of the chamber is $\sim 200 \mathrm{~L}$ when the PVF bag is fully filled. A magnetic-driven fan is set at the bottom of the reaction chamber to ensure that the reactants could be mixed rapidly and sufficiently. The experiments are performed under the atmosphere pressure with the room temperature of $\sim 293 \mathrm{~K}$. The relative humidity in the chamber is roughly estimated to be $\sim 5 \%$ due to the residual filtered air in the chamber. After the concentration of suspended pesticide particles within the reaction chamber reaches the desired value, a $\mathrm{N}_{2}$ stream with a volumetric flow rate of $0.6 \mathrm{~L} \mathrm{~min}^{-1}$ passes through the flask containing $\mathrm{N}_{2} \mathrm{O}_{5}$ powder that is placed at the room temperature, and introduces gaseous $\mathrm{N}_{2} \mathrm{O}_{5}$ continuously into the chamber during the particulate reaction with the fan turned on.

The TOF mass spectra of particulate OPPs and their reaction products are obtained in real-time with the VUV-ATOFMS (Shu et al., 2008). Only a brief description of the VUV-ATOFMS is presented here. It consists of three collimated chambers: a source chamber, a differential chamber, and a detection chamber. An $8 \mathrm{~mm}$ diameter copper rod coupled with a cartridge heater placed in the detection chamber is used to vaporize the particles, the nascent organic vapor is photoionized with VUV light emitted from a VUV light lamp with a photon flux of $5 \times 10^{14}$ photons $\mathrm{s}^{-1}$ and a photon energy of $10 \mathrm{eV}$ (Shu et al., 2008).

The $\mathrm{NO}_{3}$ radicals are generated by thermal decomposition of $\mathrm{N}_{2} \mathrm{O}_{5}$. During the experiment, the flask containing $\mathrm{N}_{2} \mathrm{O}_{5}$ powder is placed at room temperature of $\sim 293 \mathrm{~K}$. The vapor pressure of $\mathrm{N}_{2} \mathrm{O}_{5}$ at $293 \mathrm{~K}$ is $\sim 2.12 \mathrm{kPa}$ (Yaws, 1999). $\mathrm{N}_{2} \mathrm{O}_{5}$ quickly decomposes at room temperature and is in the dynamic equilibrium with $\mathrm{NO}_{2}$ and $\mathrm{NO}_{3}$ radicals, the concentrations of gaseous $\mathrm{N}_{2} \mathrm{O}_{5}$ and $\mathrm{NO}_{3}$ radicals are respectively estimated about $10^{12}-10^{13}$ and $10^{11}-10^{12}$ molecules $\mathrm{cm}^{-3}$ in the reaction chamber using an equilibrium constant of $2.9 \times 10^{-11} \mathrm{~cm}^{3}$ molecule ${ }^{-1}$ (Finlayson-Pitts and Pitts, 1999).

\subsection{Gas chromatography/mass spectrometry (GC/MS)}

In order to assign the TOF mass spectra of reaction products, $\mathrm{GC} / \mathrm{MS}$ analysis is performed to identify the products in the reaction between $\mathrm{NO}_{3}$ radicals and the coating of the pesticide. The coating is prepared by nitrogen-purging of the pesticide solution with $\sim 2 \mathrm{~mL}\left(\sim 15 \mathrm{~g} \mathrm{~L}^{-1}\right.$ in $\left.\mathrm{CH}_{2} \mathrm{Cl}_{2}\right)$ in a $150 \mathrm{~mL}$ conical flask. During the reaction, a synthetic air flow of $0.6 \mathrm{~L} \mathrm{~min}^{-1}$ containing gaseous $\mathrm{N}_{2} \mathrm{O}_{5}$ passes through the conical flask for $\sim 5 \mathrm{~min}$. After reaction, $100 \mathrm{~mL} \mathrm{CH} \mathrm{Cl}_{2}$ is added into the conical flask. Then, the conical flask is ultrasonic-washed for $\sim 5 \mathrm{~min}$. A part of the solution is atomized into suspended droplets, and the generated droplets are directly analyzed with the VUV-ATOFMS, which serves as the auxiliary experiment for product identification by contrast with the TOF mass spectra obtained from the particulate reaction. In this experiment, the TOF mass spectra of the products from the reaction between $\mathrm{NO}_{3}$ radicals and the coating of the pesticide are similar to those from the particulate reaction. Meanwhile, another part of the solution is used for product identification by GC/MS.

An Agilent $6890 \mathrm{GC} / \mathrm{MS}$ equipped with a $30 \mathrm{~m} \times 0.25 \mathrm{~mm} \times 0.25$ um HP-5 capillary and an HP-5973 quadrupole mass filter with a $70 \mathrm{eV}$ electron impact ionizer is used to identify the products. $1 \mu \mathrm{L}$ sample is injected via the pulsed splitless mode. The temperature settings of GC/MS for the measurements of the three OPPs and their derivates are adopted from the previous studies (Gallardo et al., 2006; Tsakirakis and Machera, 2007; Zhang et al., 2010b). The reaction products are analyzed by GC/MS in the total ion chromatogram (TIC) mode and identified by comparing the EI mass spectra of the products with those from a Mass Spectral Library (the National Institute of Standards and Technology (NIST) 2005). Compared with the available mass spectra in the NIST 2005 library, the product with the match rate over $85 \%$ could be identified. The mass range from 50 to $500 \mathrm{amu}$ is used in the process of data acquisition. The scanning times for parathion, malathion, and fenthion are $17.9,44$, and $24.9 \mathrm{~min}$, respectively. Data acquisition and processing are controlled by a HP Chemstation data system. Table 1 shows the reaction products detected and identified by GC/MS.

\section{Results and discussion}

\subsection{Reaction of parathion particles with $\mathrm{NO}_{3}$ radicals}

The TOF mass spectrum of parathion particles shown in Fig. $1 \mathrm{~A}$ is obtained before exposure to $\mathrm{NO}_{3}$ radicals. The most intense mass 
Table 1

Products detected and identified with GC/MS and VUV-ATOFMS.

\begin{tabular}{|c|c|c|c|c|c|}
\hline Compounds & Formula & MW & RT & $\eta_{1}$ & $\eta_{2}$ \\
\hline Paraoxon (Product $\mathrm{I}^{\mathrm{a}}$ ) & $\mathrm{C}_{10} \mathrm{H}_{14} \mathrm{NO}_{6} \mathrm{P}$ & 275 & 14.4 & $0.38^{\mathrm{a}}$ & $1^{\mathrm{a}}$ \\
\hline Malaoxon (Product $\mathrm{I}^{\mathrm{b}}$ ) & $\mathrm{C}_{10} \mathrm{H}_{19} \mathrm{O}_{7} \mathrm{PS}$ & 314 & 21.5 & $1^{\mathrm{b}}$ & $1^{\mathrm{b}}$ \\
\hline 1,2-Dicarbethoxyethyl-dimethoxyphosphinyldisulfide (Product II ${ }^{\mathrm{b}}$ ) & $\mathrm{C}_{10} \mathrm{H}_{19} \mathrm{O}_{7} \mathrm{PS}_{2}$ & 346 & - & - & $0.12^{\mathrm{b}}$ \\
\hline 2-Mercapto-succinic acid diethylester (Product III ${ }^{\mathrm{b}}$ ) & $\mathrm{C}_{8} \mathrm{H}_{14} \mathrm{O}_{4} \mathrm{~S}$ & 206 & - & - & $0.14^{\mathrm{b}}$ \\
\hline Bis(1,2-bis-ethoxycarbonylethyl)disulfide (Product IV ${ }^{\mathrm{b}}$ ) & $\mathrm{C}_{16} \mathrm{H}_{26} \mathrm{O}_{8} \mathrm{~S}_{2}$ & 410 & 26.9 & $0.017^{\mathrm{b}}$ & $0.075^{\mathrm{b}}$ \\
\hline Fenoxon $\left(\right.$ Product $\mathrm{I}^{\mathrm{C}}$ ) & $\mathrm{C}_{10} \mathrm{H}_{15} \mathrm{O}_{4} \mathrm{PS}$ & 262 & 11.0 & $0.28^{\mathrm{c}}$ & - \\
\hline Fenthion sulfoxide (Product II ${ }^{\mathrm{c}}$ ) & $\mathrm{C}_{10} \mathrm{H}_{15} \mathrm{O}_{4} \mathrm{PS}_{2}$ & 294 & 15.4 & $1^{\mathrm{c}}$ & $0.17^{\mathrm{c}}$ \\
\hline Fenoxon sulfoxide (Product III') & $\mathrm{C}_{10} \mathrm{H}_{15} \mathrm{O}_{5} \mathrm{PS}$ & 278 & 14.2 & $0.072^{\mathrm{c}}$ & $1^{\mathrm{c}}$ \\
\hline Fenthion sulfone (Product IV ${ }^{\mathrm{c}}$ ) & $\mathrm{C}_{10} \mathrm{H}_{15} \mathrm{O}_{5} \mathrm{PS}_{2}$ & 310 & 16.4 & $0.001^{\mathrm{c}}$ & - \\
\hline Fenoxon sulfone (Product V $\mathrm{V}^{\mathrm{c}}$ ) & $\mathrm{C}_{10} \mathrm{H}_{15} \mathrm{O}_{6} \mathrm{PS}$ & 294 & 14.5 & $0.1^{\mathrm{c}}$ & $0.17^{\mathrm{c}}$ \\
\hline Nitro-fenoxon sulfoxide (Product VI ${ }^{\mathrm{c}}$ ) & $\mathrm{C}_{10} \mathrm{H}_{14} \mathrm{NO}_{7} \mathrm{PS}$ & 323 & - & - & $0.075^{\mathrm{c}}$ \\
\hline
\end{tabular}

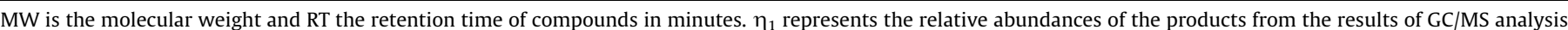

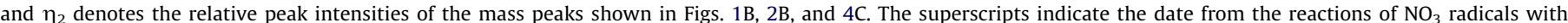
parathion (a), malathion (b), and fenthion (c).

peak at $m / z 291$ corresponds to the molecular ion of parathion, and the ion peak at $m / z 275$ is assigned as its daughter ion formed by losing an oxygen atom through VUV photoionization. The mass spectrum shown in Fig. 1B is acquired $200 \mathrm{~s}$ after the injection of $\mathrm{NO}_{3}$ radicals. The intensity of the mass peak at $m / z 291$ decreases along with the reaction time, while the intensity of the ion peak at $\mathrm{m} / z 275$ increases. GC/MS analyses (See Fig. 1C and Table 1) show that paraoxon (Product $\mathrm{I}^{\mathrm{a}}, \mathrm{C}_{10} \mathrm{H}_{14} \mathrm{NO}_{6} \mathrm{P}$, mol. wt 275) is the only
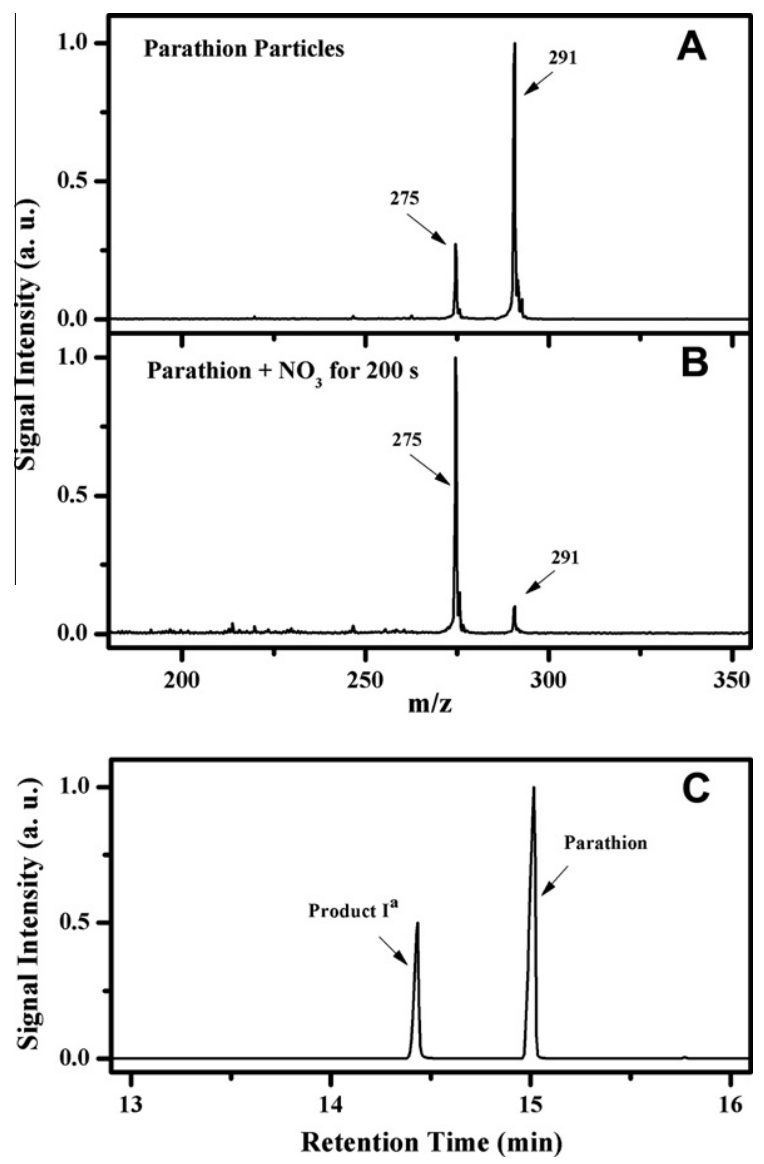

Fig. 1. TOF mass spectra of parathion particles $(\mathrm{A})$ and its oxidation products in the reaction with $\mathrm{NO}_{3}$ radicals (B), and $\mathrm{GC} / \mathrm{MS}$ total ion chromatograms (C) of the oxidation products in the reaction between $\mathrm{NO}_{3}$ radicals and the coating of parathion. The spectrum shown in Fig. $1 \mathrm{~B}$ is acquired $200 \mathrm{~s}$ after $\mathrm{NO}_{3}$ radicals are introduced into the reaction chamber. The acquisition time for each mass spectrum is $10 \mathrm{~s}$. The TOF mass spectra and the GC/MS total ion chromatogram are normalized to their most intense peaks, respectively. reaction product in the reaction between $\mathrm{NO}_{3}$ radicals and the coating of parathion. Thus, it suggests that the phenomena result from the formation of Product $\mathrm{I}^{\mathrm{a}}$, a common degradation product of parathion through photolysis, biological metabolism, and advanced oxidation process (Gallardo et al., 2006; Wu and Linden, 2008; Fan et al., 2011). As a derivate of parathion, its intoxication symptoms are similar to those produced by other cholinesterase inhibitors (Gallardo et al., 2006).

\subsection{Reaction of malathion particles with $\mathrm{NO}_{3}$ radicals}

Fig. 2A shows the TOF mass spectrum of malathion particles before exposure to $\mathrm{NO}_{3}$ radicals. The mass peak at $m / z 330$ is contributed from the molecular ion of malathion, and the most intense mass peak at $m / z 173$ is assigned as its daughter ion formed by removing a $\mathrm{C}_{2} \mathrm{H}_{6} \mathrm{O}_{2} \mathrm{PS}_{2}$ group (mol. wt 157) via the cleavage of the $\mathrm{C}-\mathrm{S}$ bond through VUV photoionization. The ion peaks at $\mathrm{m} / \mathrm{z}$ 256 and 284 are tentatively assigned to the daughter ions of malathion, which may be respectively produced by the losses of an ethyl ester group $\left(\mathrm{C}_{3} \mathrm{H}_{6} \mathrm{O}_{2}\right.$, mol. wt 74$)$ and an ethanol group $\left(\mathrm{C}_{2} \mathrm{H}_{6} \mathrm{O}\right.$, mol. wt 46$)$ through VUV photoionization. The ion peak at $m / z 188$ is not successfully assigned, which may be the daughter ion of malathion. The small mass peak at $m / z 220$ is contributed from the pump oil in the instrument and is not discussed in the paper.

The TOF mass spectrum shown in Fig. $2 \mathrm{~B}$ is acquired $60 \mathrm{~s}$ after the injection of $\mathrm{NO}_{3}$ radicals into the reaction chamber. Compared with the TOF mass spectrum shown in Fig. 2A, some new mass peaks appear at $m / z 204,206,224,268,300,314,346$, and 410. Based on GC/MS analyses (see Fig. $2 \mathrm{C}$ and Table 1), malaoxon (Product $\mathrm{I}^{\mathrm{b}}, \mathrm{C}_{10} \mathrm{H}_{19} \mathrm{O}_{7} \mathrm{PS}$, mol. wt 314) and bis(1,2-bis-ethoxycarbonylethyl)disulfide (Product $\mathrm{IV}^{\mathrm{b}}, \mathrm{C}_{16} \mathrm{H}_{26} \mathrm{O}_{8} \mathrm{~S}_{2}$, mol. wt 410 ) are identified as the two products in the reaction between $\mathrm{NO}_{3}$ radicals and the coating of malathion, and their retention times are 21.5 and $26.9 \mathrm{~min}$, respectively.

Thus, the mass peaks at $m / z 314$ and 410 are assigned to the molecular ions of Products $\mathrm{I}^{\mathrm{b}}$ and $\mathrm{IV}^{\mathrm{b}}$, respectively. Product $\mathrm{I}^{\mathrm{b}}$ is the main oxidative degradation product of malathion in the natural environment (Kaur et al., 1997; Bavcon et al., 2003), and shows approximately 10 -fold more toxic than its parent chemical (Snawder and Chambers, 1989). The ion peak at $m / z 268$ is tentatively assigned to the daughter ion of Products $\mathrm{I}^{\mathrm{b}}$, which may be formed by removing an ethanol group $\left(\mathrm{C}_{2} \mathrm{H}_{6} \mathrm{O}\right.$, mol. wt 46) through VUV photoionization. The mass peak at $m / z 346$ is tentatively assigned to the molecular ion of 1,2-dicarbethoxyethyl-dimethoxyphosphinyldisulfide (Product II ${ }^{\mathrm{b}}, \mathrm{C}_{10} \mathrm{H}_{19} \mathrm{O}_{7} \mathrm{PS}_{2}$, mol. wt 346), and the ion peak at $m / z 300$ is assigned as its daughter ion, formed by the loss of an ethanol group $\left(\mathrm{C}_{2} \mathrm{H}_{6} \mathrm{O}\right.$, mol. wt 46$)$ through VUV photoionization. 

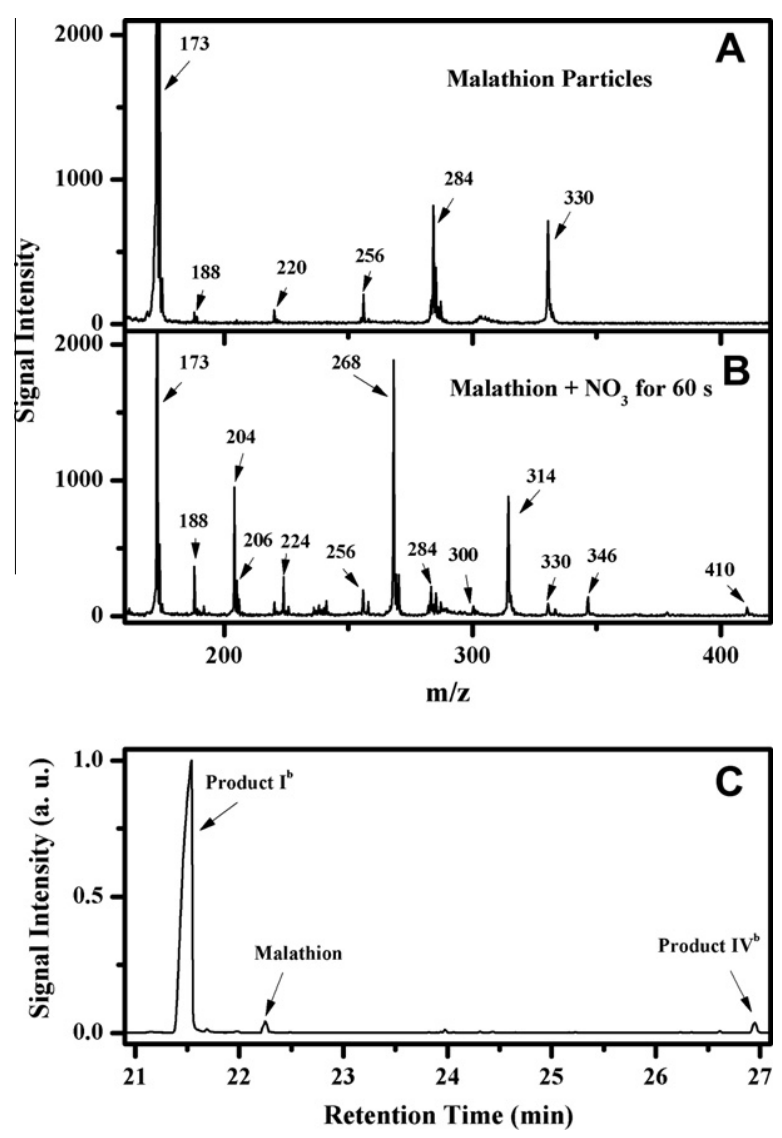

Fig. 2. TOF mass spectra of malathion particles $(A)$ and its oxidation products in the reaction with $\mathrm{NO}_{3}$ radicals (B), and GC/MS total ion chromatograms (C) of the oxidation products in the reaction between $\mathrm{NO}_{3}$ radicals and the coating of malathion. The spectrum shown in Fig. $2 \mathrm{~B}$ is acquired $60 \mathrm{~s}$ after $\mathrm{NO}_{3}$ radicals are introduced into the reaction chamber. The acquisition time for each mass spectrum is $10 \mathrm{~s}$. The GC/MS total ion chromatogram is normalized to its most intense peak.

Products $\mathrm{I}^{\mathrm{b}}$ and $\mathrm{II}^{\mathrm{b}}$ are both reported as the products of malathion through peracid oxidation (Bellet and Casida, 1974). The ion peak at $m / z 204$ is tentatively assigned to the daughter ion of 2-mercapto-succinic acid diethylester (Product $\mathrm{III}^{\mathrm{b}}, \mathrm{C}_{8} \mathrm{H}_{14} \mathrm{O}_{4} \mathrm{~S}$, mol. wt 206), which is a common hydrolytic product of malathion in water and soil (Kaur et al., 1997). The mass peak at $m / z 204$ may result from the loss of one hydrogen molecule from Product III $^{\mathrm{b}}$ through VUV photoionization (Meng et al., 2010). The mass peaks at $\mathrm{m} / \mathrm{z}$ 188 and 224 are not assigned successfully, which may be the daughter ion of the reaction products. Products $\mathrm{II}^{\mathrm{b}}$ and $\mathrm{III}^{\mathrm{b}}$ are not detected by GC/MS, which may be due to their thermal instability (Bellet and Casida, 1974) and chemical polarity. The four assigned products are also observed in the heterogeneous reaction of suspended malathion particles with ozone (Meng et al., 2010).

The EI mass spectrum of Product IV ${ }^{\mathrm{b}}$ shown in Fig. 3 is obtained by GC/MS, of which the standard EI mass spectrum is not available yet in NIST library. Thus, the mass peak at $m / z 410$ in the EI mass spectrum is deemed to be the molecular ion of Product IV ${ }^{\mathrm{b}}$. The specific fragment ion at $m / z 365$ might be formed by the loss of an ethoxy group $\left(\mathrm{C}_{2} \mathrm{H}_{5} \mathrm{O}\right.$, mol. wt 45$)$ from the molecular ion, and the successive losses of an ethoxy group $\left(\mathrm{C}_{2} \mathrm{H}_{5} \mathrm{O}\right.$, mol. wt 45$)$ and an ethyl group $\left(\mathrm{C}_{2} \mathrm{H}_{5}\right.$, mol. wt 29$)$ from the daughter ion at $\mathrm{m} / z$ 365 may produce the dominant fragment ion at $m / z 291$. The mass peak at $\mathrm{m} / \mathrm{z} 205$ could be formed via the cleavage of $\mathrm{S}-\mathrm{S}$ bond of the molecular ion at $m / z 410$. The loss of an ethyl ester group $\left(\mathrm{C}_{3} \mathrm{H}_{6} \mathrm{O}_{2}\right.$, mol. wt 74) via the breakage of $\mathrm{C}-\mathrm{C}$ bond of the fragment ion at $m / z 205$ might produce fragment ion at $m / z 131\left(\mathrm{C}_{5} \mathrm{H}_{7} \mathrm{O}_{2} \mathrm{~S}\right.$,

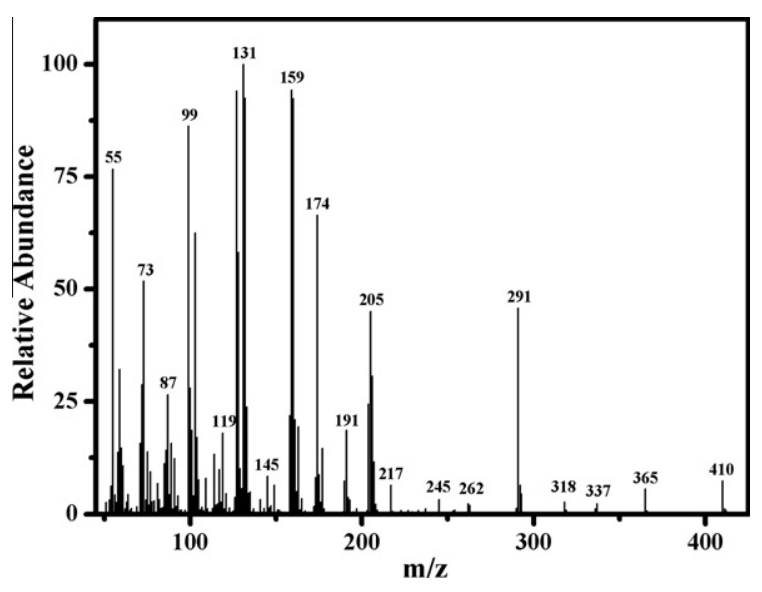

Fig. 3. EI mass spectrum of bis(1,2-bis-ethoxycarbonylethyl)disulfide (Product IV ${ }^{\mathrm{b}}$ ) obtained in the experiments.

mol. wt 131). The fragment ion at $\mathrm{m} / z 99\left(\mathrm{C}_{5} \mathrm{H}_{7} \mathrm{O}_{2}\right.$, mol. wt 99) might be formed by removing a sulfur atom from the fragment ion at $m / z 131$.

\subsection{Reaction of fenthion particles with $\mathrm{NO}_{3}$ radicals}

Fig. 4A shows the TOF mass spectrum of fenthion particles in the absence of $\mathrm{NO}_{3}$ radicals. The mass peak at $m / z 278$ corresponds to the molecular ion of fenthion. The mass spectra shown in Fig. $4 \mathrm{~B}$ and $\mathrm{C}$ are acquired 60 and $140 \mathrm{~s}$ after the injection of $\mathrm{NO}_{3}$ radicals into the chamber. Compared with the mass spectrum shown in Fig. 4A, there are new mass peaks appearing at $m / z 220,247$, $263,279,294,307$, and 323 in the TOF mass spectra shown in Fig. $4 \mathrm{~B}$ and $\mathrm{C}$.

Through GC/MS analyses, fenoxon (Product $\mathrm{I}^{\mathrm{c}}, \mathrm{C}_{10} \mathrm{H}_{15} \mathrm{O}_{4} \mathrm{PS}$, mol. wt 262), fenthion sulfoxide (Product $\mathrm{II}^{\mathrm{c}}, \mathrm{C}_{10} \mathrm{H}_{15} \mathrm{O}_{4} \mathrm{PS}_{2}$, mol. wt 294), fenoxon sulfoxide (Product III ${ }^{\mathrm{c}}, \mathrm{C}_{10} \mathrm{H}_{15} \mathrm{O}_{5} \mathrm{PS}$, mol. wt 278), fenthion sulfone (Product IV $\mathrm{IV}^{\mathrm{c}} \mathrm{C}_{10} \mathrm{H}_{15} \mathrm{O}_{5} \mathrm{PS}_{2}$, mol. wt 310 ), and fenoxon sulfone (Product $\mathrm{V}^{\mathrm{c}}, \mathrm{C}_{10} \mathrm{H}_{15} \mathrm{O}_{6} \mathrm{PS}$, mol. wt 294) are obtained as the five products in the reaction between $\mathrm{NO}_{3}$ radicals and the coating of fenthion. Their retention times are 11.0, 15.4, 14.2, 16.4, and $14.5 \mathrm{~min}$ (see Fig. 4D and Table 1 ), respectively. Thus, the mass peaks at $m / z 294$ shown in Fig. $4 \mathrm{~B}$ and $\mathrm{C}$ might be contributed from both Products $\mathrm{II}^{\mathrm{c}}$ and $\mathrm{V}^{\mathrm{c}}$, and the mass peaks at $\mathrm{m} / \mathrm{z} 278$ possibly from Product $\mathrm{III}^{\mathrm{c}}$ and residual fenthion. These five products are common degradation products of fenthion in the natural environment (Cabras et al., 1993; Minelli et al., 1996; Pico et al., 2007; Tsakirakis and Machera, 2007), and show higher toxicity than fenthion (Cabras et al., 1993).

It was reported that fenthion was converted into Product II $^{\mathrm{c}}$ rapidly during sunlight photolysis (Minelli et al., 1996). Besides, GC/ MS analyses show that the yield of Product $\mathrm{II}^{\mathrm{C}}$ is one order of magnitude more than that of Product $\mathrm{V}^{\mathrm{c}}$. Therefore, the first mass peak $(\mathrm{m} / z 294)$ appearing in the reaction process shown in Fig. 4B is mainly contributed from the molecular ion of Product II $^{\mathrm{c}}$. The mass peaks at $m / z 247,263$, and 279 in Fig. 4B are tentatively assigned to the daughter ions of Product II ${ }^{\mathrm{c}}$. The fragment at $m / z 279$ may be formed by the loss of a methyl group $\left(\mathrm{CH}_{3}\right.$, mol. wt 15) through VUV photoionization, and the successive loss of oxygen atom from the fragment ion at $\mathrm{m} / \mathrm{z} 279$ yields fragment ions at $\mathrm{m} / \mathrm{z} 263$ and 247.

Since the EI mass spectrum in NIST library of Product III ${ }^{\mathrm{c}}$ shows a strong daughter ion mass peak at $m / z 263$, the most intense mass peak at $m / z 263$ shown in Fig. 4C is assigned as the daughter ion of Product III ${ }^{\mathrm{c}}$, produced by losing a methyl group $\left(\mathrm{CH}_{3}\right.$, mol. wt 15$)$ 

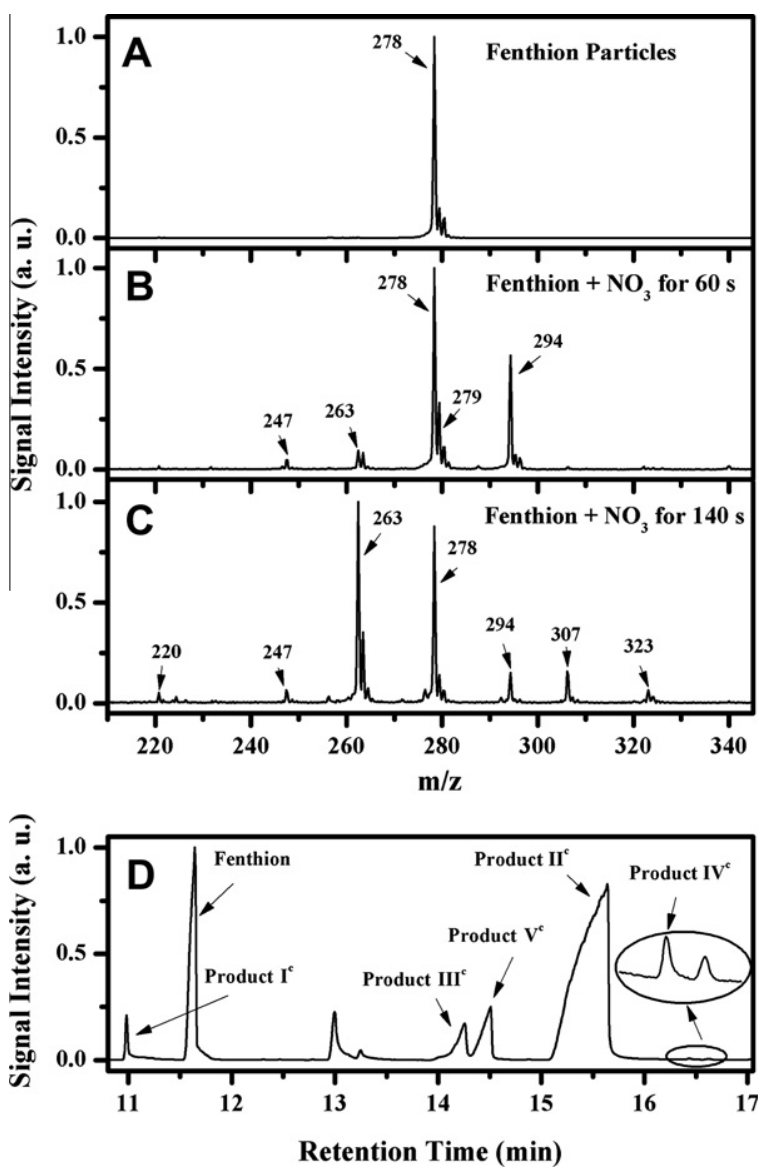

Fig. 4. TOF mass spectra of the fenthion particles $(A)$ and its oxidation products in the reaction with $\mathrm{NO}_{3}$ radicals ( $\mathrm{B}$ and $\mathrm{C}$ ), and $\mathrm{GC} / \mathrm{MS}$ total ion chromatograms (D) of the oxidation products in the reaction between $\mathrm{NO}_{3}$ radicals and the coating of fenthion. The spectra shown in Fig. 3B and $\mathrm{C}$ are acquired 60 and $140 \mathrm{~s}$ after $\mathrm{NO}_{3}$ radicals are introduced into the reaction chamber. The acquisition time for each mass spectrum is $10 \mathrm{~s}$. The TOF mass spectra and the GC/MS total ion chromatogram are normalized to their most intense peaks, respectively.

through VUV photoionization. Considering the mass spacing of 45 amu between $m / z 278$ and 323, we speculate that the mass peak at $\mathrm{m} / \mathrm{z} 323$ results from the nitro-substituted product of Product III ${ }^{\mathrm{C}}$ (Liu et al., 2011). Thus, the mass peak at $m / z 323$ is tentatively assigned to the molecular ion of nitro-fenoxon sulfoxide (Product $\mathrm{VI}^{\mathrm{c}}$, $\mathrm{C}_{10} \mathrm{H}_{14} \mathrm{NO}_{7} \mathrm{PS}$, mol. wt 323), and the ion peak at $m / z 307$ is tentatively assigned as its daughter ion formed by removing an oxygen atom through VUV photoionization. Products $\mathrm{I}^{\mathrm{c}}$ and $\mathrm{IV}^{\mathrm{c}}$ are only detected by GC/MS while the confirmation of Product $\mathrm{VI}^{\mathrm{c}}$ by GC/MS is not successfully achieved. These inconsistencies may result from the different detection limits of two analytical instruments (Gao et al., 2008).

\subsection{Degradations of parathion, malathion, and fenthion}

The initial mass concentrations of parathion, malathion, and fenthion in the chamber are 572,654 , and $407 \mu \mathrm{g} \mathrm{m}^{-3}$, respectively. Since the concentrations of the particles are linear to their signal intensities obtained by the VUV-ATOFMS (Shu et al., 2008), the decay rates of the signal intensities are equal to the decay rates of the concentrations of OPPs particles. Therefore, the residual concentrations of parathion, malathion, and fenthion in the chamber are calculated to be $5.7,5.8$, and $2.1 \mu \mathrm{g} \mathrm{m}^{-3}$, respectively. The data points shown in Fig. 5 are the time-dependent signal intensities of OPPs particles normalized to their initial intensities. The

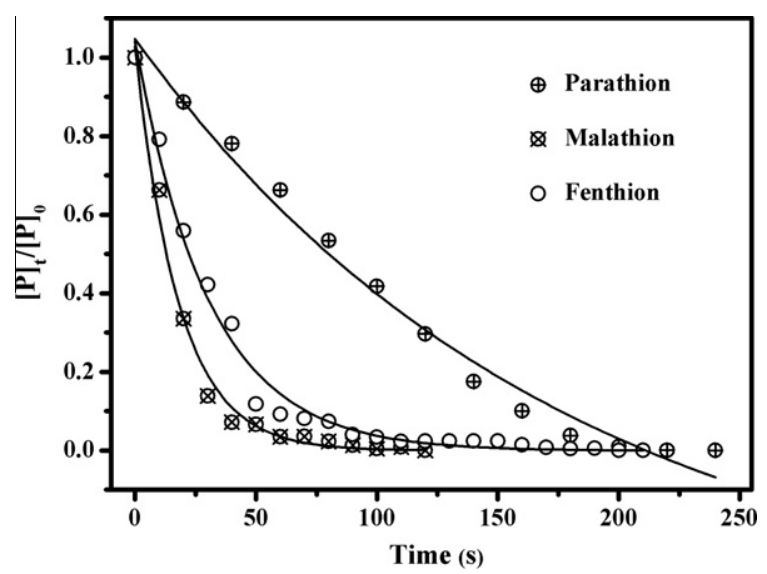

Fig. 5. Decay curves of parathion, malathion, and fenthion particles at the concentration of $\mathrm{NO}_{3}$ radicals about $10^{11}-10^{12}$ molecules $\mathrm{cm}^{-3}$.
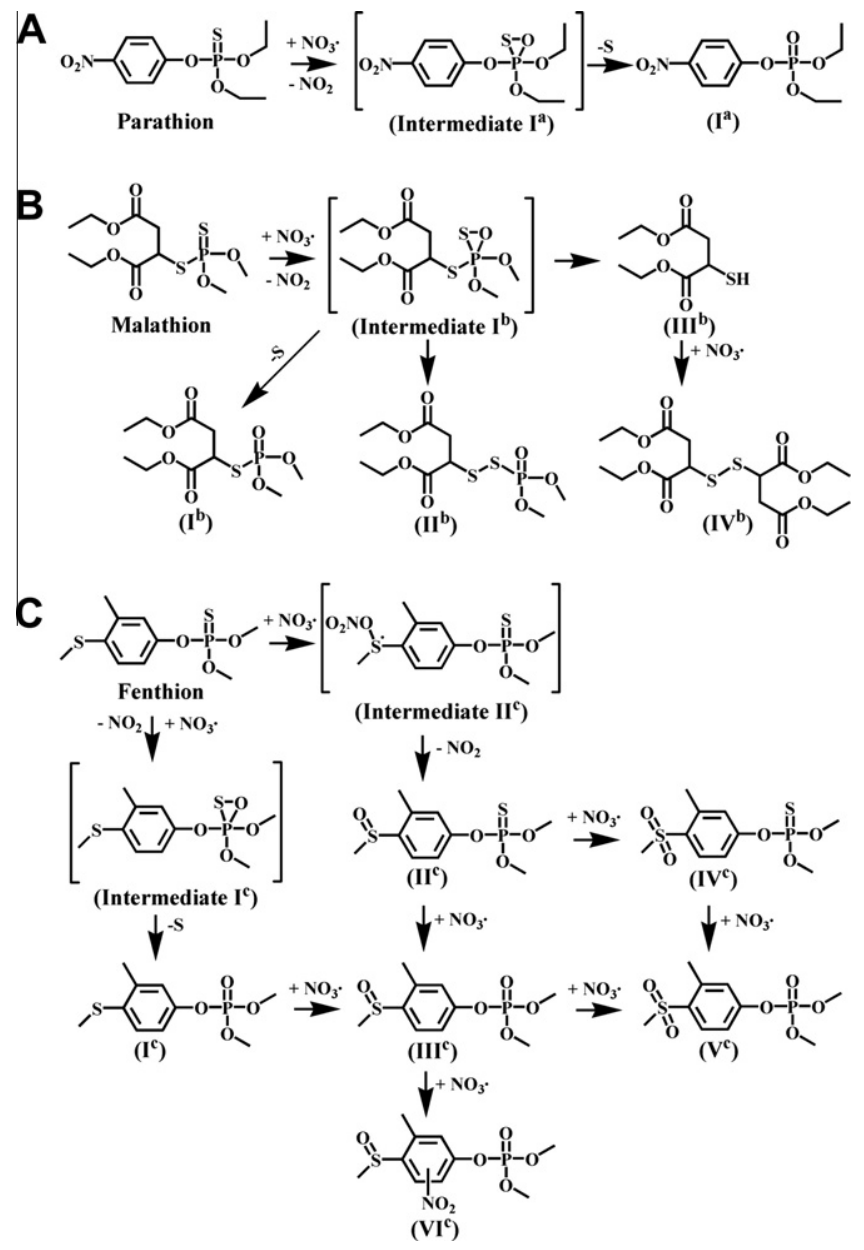

Fig. 6. Proposed pathways for the reactions of $\mathrm{NO}_{3}$ radicals with parathion, malathion, and fenthion particles.

degradation rates of parathion, malathion, and fenthion under the experimental conditions are $5.5 \times 10^{-3}, 5.6 \times 10^{-2}$, and $3.3 \times$ $10^{-2} \mathrm{~s}^{-1}$, respectively, obtained by fitting the data points with an exponential decay via non-linear least square fitting $\left(R^{2}>0.98\right)$. These experimental results suggest that the reactivity of parathion toward $\mathrm{NO}_{3}$ radicals is much less than those of malathion and fenthion. 


\subsection{Reaction pathways of parathion, malathion, and fenthion}

It has been reported that the reactions of organothiophosphorus compounds are usually initiated by the addition of oxidants to the sulfur atom or to the $\mathrm{P}=\mathrm{S}$ double bond, giving one or more unstable intermediates (Bellet and Casida, 1974). Thus, Intermediates $\mathrm{I}^{\mathrm{a}}, \mathrm{I}^{\mathrm{b}}$, and $\mathrm{I}^{\mathrm{c}}$ are speculated to be formed by the addition of $\mathrm{NO}_{3}$ radicals to the $\mathrm{P}=\mathrm{S}$ moiety, accompanying with the loss of a $\mathrm{NO}_{2}$ molecule (Liu et al., 2011). These intermediates respectively yield Products $\mathrm{I}^{\mathrm{a}}, \mathrm{I}^{\mathrm{b}}$, and $\mathrm{I}^{\mathrm{c}}$ via the loss of a sulfur atom from the cyclic $\mathrm{P}-\mathrm{O}-\mathrm{S}$ group (See Fig. 6A-C) (Liu et al., 2011). Product II $^{\mathrm{b}}$ of malathon is formed through the intermolecular rearrangement of Intermediate $\mathrm{I}^{\mathrm{b}}$ (Bellet and Casida, 1974). Product III ${ }^{\mathrm{b}}$ might result from the cleavage of P-S bond from Intermediate $\mathrm{I}^{\mathrm{b}}$ and subsequent radical-molecule reaction, and Product III $^{\mathrm{b}}$ might be further oxidized into Product $\mathrm{IV}^{\mathrm{b}}$ (Meng et al., 2010). The formation mechanism of Product $I^{\mathrm{b}}$ may be similar to that of bis(4-chlorophenyl)disulfide in the oxidation of 0,0 -diethyl S-(4-chlorophenyl) phosphorodithioate (Miyamoto and Yamamoto, 1977). The degradation pathways of malathion particles toward $\mathrm{NO}_{3}$ radicals obtained in this study are similar to that of ozonation of malathion particles (Meng et al., 2010).

Product $\mathrm{I}^{\mathrm{c}}$ of fenthion could be converted into Products $\mathrm{III}^{\mathrm{c}}$ and $\mathrm{V}^{\mathrm{c}}$ by the oxidation of the sulfur atom on the methylthio group (Cabras et al., 1993; Minelli et al., 1996; Pico et al., 2007). Product II ${ }^{\mathrm{C}}$ of fenthion observed in the experiment suggests that Intermediate $\mathrm{II}^{\mathrm{C}}$ could be formed in the reaction of fenthion particles with $\mathrm{NO}_{3}$ radicals (See Fig. 6C). It might be formed by the attack of the $\mathrm{NO}_{3}$ radical on the sulfur atom on the methylthio group of fenthion, then yielding Product $\mathrm{II}^{\mathrm{c}}$ by losing a $\mathrm{NO}_{2}$ molecule. Products II $^{\mathrm{c}}$ undergoes subsequent oxidation of the sulfur atom on the methylthio group by $\mathrm{NO}_{3}$ radicals, forming Products $\mathrm{IV}^{\mathrm{c}}$. In addition, the oxidation of Products II ${ }^{\mathrm{c}}$ and $\mathrm{IV}^{\mathrm{c}}$ could lead to the formations of Products III $^{\mathrm{c}}$ and V ${ }^{\mathrm{c}}$, respectively (Cabras et al., 1993; Minelli et al., 1996). Product $\mathrm{III}^{\mathrm{c}}$ can be converted into Product $\mathrm{VI}^{\mathrm{c}}$ via further reaction with the $\mathrm{NO}_{3}$ radical, of which the formation mechanism may be similar to that of nitro-substituted products of carbaryl particles in the reaction with $\mathrm{NO}_{3}$ radicals (Yang et al., 2011). There are some discrepancies between the proposed pathways in this study and those of fenthion in oranges (Pico et al., 2007), which might be mainly due to the difference in degradation circumstances.

\section{Conclusions}

In this study, the VUV-ATOFMS is used to online analyze the particulate products of heterogeneous reactions of $\mathrm{NO}_{3}$ radicals with parathion, malathion, and fenthion adsorbed on azelaic acid particles. Assisted with GC/MS analysis, paraoxon is identified as the only reaction product of parathion. Malaoxon and bis(1,2-bisethoxycarbonylethyl)disulfide are identified in the reaction of malathion with $\mathrm{NO}_{3}$ radicals. Fenoxon, fenoxon sulfoxide, fenthion sulfoxide, fenoxon sulfone, and fenthion sulfone are detected and identified as the reaction products of fenthion. Meanwhile, 2-mercapto-succinic acid diethylester, 1,2-dicarbethoxyethyl-dimethoxyphosphinyldisulfide, and nitro-fenoxon sulfoxide are observed by the VUV-ATOFMS but not identified by GC/MS. It was reported that the oxygen analog $(\mathrm{P}=\mathrm{O})$ of OPPs had more effective toxicity than its thiophosphoryl function $(\mathrm{P}=\mathrm{S}$ ) (Yan et al., 2008). Then, we speculate that the potential risks of these products to human health are much severer than their parent chemicals. Under the experimental conditions, the degradation rates of parathion, malathion, and fenthion are $5.5 \times 10^{-3}$, $5.6 \times 10^{-2}$, and $3.3 \times 10^{-2} \mathrm{~s}^{-1}$, respectively. The degradation pathways of the three OPPs in the reactions with $\mathrm{NO}_{3}$ radicals are proposed. The experimental results might shed light on the chemical transformations of the three OPPs through oxidation by $\mathrm{NO}_{3}$ radicals in the atmosphere.

\section{Acknowledgements}

This research is funded by Creative Research Groups of China (Grant No. 50921064) and National Natural Science Foundation of China (Grant No. 21077115).

\section{References}

Atkinson, R. (Ed.), 1995. Gas Phase Tropospheric Chemistry of Organic Compounds. Royal Society of Chemistry, London.

Bavcon, M., Trebse, P., Zupancic-Kralj, L., 2003. Investigations of the determination and transformations of diazinon and malathion under environmental conditions using gas chromatography coupled with a flame ionisation detector. Chemosphere 50, 595-601.

Bellet, E.M., Casida, J.E., 1974. Products of peracid oxidation of organothiophosphorus compounds. J. Agric. Food Chem. 22, 207-211.

Cabras, P., Garau, V.L., Melis, M., Pirisi, F.M., Spanedda, L., 1993. Persistence and fate of fenthion in olives and olive products. J. Agric. Food Chem. 41, 2431-2433.

Cakir, S., Sarikaya, R., 2005. Genotoxicity testing of some organophosphate insecticides in the Drosophila wing spot test. Food. Chem. Toxicol. 43, 443-450.

Fan, C.H., Tsui, L., Liao, M.C., 2011. Parathion degradation and its intermediate formation by Fenton process in neutral environment. Chemosphere 82, 229236

Ferrando, M.D., Alarcon, V., Fernandezcasalderrey, A., Gamon, M., Andreumoliner, E., 1992. Persistence of some pesticides in the aquatic environment. B. Environ. Contam. Tox. 48, 747-755.

Finlayson-Pitts, B.J., Pitts, J.N., Jr. (Eds.), 1999. Chemistry of the Upper and Lower Atmosphere. Academic Press, NYC, USA.

Gallardo, E., Barroso, M., Margalho, C., Cruz, A., Vieira, D.N., Lopez-Rivadulla, M., 2006. Determination of parathion in biological fluids by means of direct solidphase microextraction. Anal. Bioanal. Chem. 386, 1717-1726.

Gao, S.K., Zhang, Y., Li, Y., Meng, J.W., He, H., Shu, J.N., 2008. A comparison between the vacuum ultraviolet photoionization time-of-flight mass spectra and the GC/ MS total ion chromatograms of polycyclic aromatic hydrocarbons contained in coal soot and multi-component PAH particles. Int. J. Mass Spectrom. 274, 64-69.

Giordano, G., Afsharinejad, Z., Guizzetti, M., Vitalone, A., Kavanagh, T.J., Costa, L.G., 2007. Organophosphorus insecticides chlorpyrifos and diazinon and oxidative stress in neuronal cells in a genetic model of glutathione deficiency. Toxicol. Appl. Pharmacol. 219, 181-189.

Jauregui, J., Valderrama, B., Albores, A., Vazquez-Duhalt, R., 2003. Microsomal transformation of organophosphorus pesticides by white rot fungi. Biodegradation 14, 397-406.

Karagulian, F., Rossi, M.J., 2005. The heterogeneous chemical kinetics of $\mathrm{NO}_{3}$ on atmospheric mineral dust surrogates. Phys. Chem. Chem. Phys. 7, 3150-3162.

Kaur, I., Mathur, R.P., Tandon, S.N., Dureja, P., 1997. Identification of metabolites of malathion in plant, water and soil by GC-MS. Biomed. Chromatogr. 11, 352355.

Kosikowska, M., Biziuk, M., 2010. Review of the determination of pesticide residues in ambient air. Trac-Trend Anal. Chem. 29, 1064-1072.

Liu, C.G., Gan, J., Zhang, Y., Liang, M., Shu, X., Shu, J.N., Yang, B., 2011. Heterogeneous reaction of suspended phosmet particles with $\mathrm{NO}_{3}$ radicals. J. Phys. Chem. A 115, 10744-10748.

Meng, J.W., Yang, B., Zhang, Y., Dong, X.Y., Shu, J.N., 2010. Heterogeneous ozonation of suspended malathion and chlorpyrifos particles. Chemosphere 79, 394-400.

Minelli, E.V., Cabras, P., Angioni, A., Garau, V.L., Melis, M., Pirisi, F.M., Cabitza, F., Cubeddu, M., 1996. Persistence and metabolism of fenthion in orange fruit. J. Agric. Food Chem. 44, 936-939.

Miyamoto, T., Yamamoto, I., 1977. Mechanism of phosphinyl disulfide formation from a phosphorodithioate ester. J. Pestic. Sci. 2, 303-310.

Naudet, J.P., Rigaud, P., Pirre, M., 1989. Altitude distribution of stratospheric $\mathrm{NO}_{3} 1$. observation of $\mathrm{NO}_{3}$ and related species. J. Geophys. Res-Atmos. 94, 6374-6382.

Pico, Y., Farre, M., Soler, C., Barcelo, D., 2007. Confirmation of fenthion metabolites in oranges by IT-MS and QqTOF-MS. Anal. Chem. 79, 9350-9363.

Pina-Guzman, B., Solis-Heredia, M.J., Quintanilla-Vega, B., 2005. Diazinon alters sperm chromatin structure in mice by phosphorylating nuclear protamines. Toxicol. Appl. Pharmacol. 202, 189-198.

Platt, U., Perner, D., Harris, G.W., Winer, A.M., Pitts, J.N., 1980. Observations of nitrous-acid in an urban atmosphere by differential optical-absorption. Nature 285, 312-314.

Shu, J.N., Gao, S.K., Li, Y., 2008. A VUV photoionization aerosol time-of-flight mass spectrometer with a RF-powered VUV lamp for laboratory-based organic aerosol measurements. Aerosol Sci. Technol. 42, 110-113.

Slotkin, T.A., Levin, E.D., Seidler, F.J., 2009. Developmental neurotoxicity of parathion: progressive effects on serotonergic systems in adolescence and adulthood. Neurotoxicol. Teratol. 31, 11-17.

Snawder, J.E., Chambers, J.E., 1989. Toxic and developmental effects of organophosphorus insecticides in embryos of the South African clawed frog. J. Environ. Sci. Health B 24, 205-218.

Tsakirakis, A., Machera, K., 2007. Determination of fenthion and oxidation products in personal protection equipment by gas chromatography. J. Chromatogr. A 1171, 98-103. 
van den Berg, F., Kubiak, R., Benjey, W.G., Majewski, M.S., Yates, S.R., Reeves, G.L., Smelt, J.H., van der Linden, A.M.A., 1999. Emission of pesticides into the air. Water Air Soil Pollut. 115, 195-218.

Vonderheide, A.P., Meija, J., Montes-Bayon, M., Caruso, J.A., 2003. Use of optional gas and collision cell for enhanced sensitivity of the organophosphorus pesticides by GC-ICP-MS. J. Anal. Atom. Spectrom. 18, 1097-1102.

Wu, C.L., Linden, K.G., 2008. Degradation and byproduct formation of parathion in aqueous solutions by $\mathrm{UV}$ and $\mathrm{UV} / \mathrm{H}_{2} \mathrm{O}_{2}$ treatment. Water Res. 42, 4780-4790.

Yan, D.Y., Jiang, X., Xu, S.H., Wang, L.G., Bian, Y.R., Yu, G.F., 2008. Quantitative structure-toxicity relationship study of lethal concentration to tadpole (Bufo vulgaris formosus) for organophosphorous pesticides. Chemosphere 71, 18091815.
Yang, B., Meng, J.W., Zhang, Y., Liu, C.G., Gan, J., Shu, J.N., 2011. Experimental studies on the heterogeneous reaction of $\mathrm{NO}_{3}$ radicals with suspended carbaryl particles. Atmos. Environ. 45, 2074-2079.

Yaws, C.L. (Ed.), 1999. Chemical Properties Handbook. McGraw-Hill, Columbus.

Zhang, Y., Yang, B., Meng, J.W., Gao, S.K., Dong, X.Y., Shu, J.N., 2010a. Homogeneous and heterogeneous reactions of phenanthrene with ozone. Atmos. Environ. 44, 697-702.

Zhang, Y.Y., Xiao, Z.Y., Chen, F., Ge, Y.Q., Wu, J.H., Hu, X.S., 2010b. Degradation behavior and products of malathion and chlorpyrifos spiked in apple juice by ultrasonic treatment. Ultrason. Sonochem. 17, 72-77. 